\title{
Research on Key Development Technologies for SPOC Platform
}

\author{
Jiujiu Yu \\ College of Computer Engineering, Anhui SanLian University, Hefei 230601, China
}

\begin{abstract}
As the derivation and innovation of MOOC (Massive Open Online Course), the development of SPOC (Small Private Online Course) platform which is based on MOOC idea can be better applied to the blended teaching of various courses in local universities in post-MOOC era. Based on the analysis of the current application of SPOC platform, from the view of technology in implementation, we explore the key technologies of identification on face recognition based on emotion calculation, course creating, editing and sharing, analysis of online learning behaviour and exercising or examining on subjective items for developing of a SPOC platform. Finally, further researches on how to construct on the targeted and distinctive mobile learning resources and smart education mode which is based on SPOC, how to provide formative assessment data and consciousness assessment data for learners accurately and function of data statistics and motivational observation that could be completed by teachers, how to cut some non-essential auxiliary functions of an existed MOOC platform for a certain local user group to form a flexible and usable SPOC platform with good expansibility are expected in the paper.
\end{abstract}

\section{Introduction}

MOOC (Massive Open Online Course) is a qualitative change in information technology of higher education for course teaching in universities. Because the micro influence on teaching in classroom will cause the macro influence on education, application on MOOC in classroom is needed to be paid more attention by teachers [1]. With the rapid development of MOOC, many Chinese MOOCs are also established on some famous MOOC platforms, such as Chinese University MOOC, NetEase cloud classroom, xuetang online, iCourse, chaoxing, and so on. In year of 2013, technical requirements (Highly scalable, Massive no. of concurrent users, Good system response, Stability, Global access and Portability) of MOOC platform were first put forward in China National Computer Congress [2]. Although the application of MOOC platform has key technologies on improving network video, optimizing discussion forums, combining with machine scoring and peer review, machine learning tracking and analysis of MOOC data, with the help of social networking, however, high-cost and excellent faculties for constructing of MOOC resources are not affordable for every university in China. Because of a wide range of MOOC learners, their learning behaviors cannot be managed effectively by teachers, and the teaching mode is relatively simple, lacking of analysis and design of hierarchical teaching target [3]. The individual demand for learners cannot be

*Corresponding author: yjjyjL@163.com satisfied. Additionally, the disadvantages of MOOC are obvious. For example, the effective teaching evaluation cannot be done through MOOC platform, and the subjective content of students' emotions or thinking ability is difficult to reflect [4]. MOOC is not suitable for some practical or experimental courses of engineering specialties in universities.

As a supplement to MOOC, SPOC (Small Private Online Course) deeply combined a large amount of learning resources with traditional classroom teaching in campus, which is not only the reform and innovation of the MOOC, but also reflects the development of traditional teaching in post-MOOC period. SPOC platforms inherit some of the advantages of MOOC platforms and they are a kind of localization-based platforms which are developed on the basis of MOOC. In fact, SPOC plays an important role on online self-learning. A SPOC platform is a better integration with $\mathrm{MOOC}$ resources and classroom teaching and it is widely used for supporting the blended learning mode. With the help of the existing MOOC platforms whatever in domestic or abroad to complete the selflearning process tend to be out of line with the actual teaching demand, and the development of the SPOC is limited [5]. At present, many universities are needed to be combining the localized teaching environment with practical teaching demand to construct the professionalfeatured MOOC resources or micro-curriculum resources, SPOC platforms with well-targeted, strong practicality, low-cost should be designed and applied to promote and 
reform of hybrid teaching mode in campus, but not the simple pile of all kinds of teaching resources only. This is also a question that needs to be considered in further development of informatization on high education in universities in post-MOOC period.

However, most of the researches on SPOC are mainly focused on two aspects of teaching mode on designing and practice on teaching recently [6]. For example, relationship structure of "time-space-learning form" based on SPOC [7], blended learning mode of SPOC-as a case of "C Program Design" course [8], online teaching mode-from MOOC to SPOC [9], innovative capability training mode based on SPOC [10], and so on. But, exploratory researches on development of the SPOC platforms are not sufficient in post-MOOC period yet. Therefore, we try to explore the development of the SPOC platform and its key technologies from the view of technical implementation in this paper.

\section{Key technologies on developing of a SPOC platform}

MOOC platform is a large-scale, complex, and open-course online learning platform which is opened to the world. In practical applications, SPOC platform is mostly for partial or local learners, such as students in a university or students for a certain subject in a university. From year of 2014, a series of famous SPOC Platforms came into being. Such as Fanya SPOC Platform (Chaoxing Corporation), izhixue SPOC Platform (Tsinghua University), CNSPOC Cloud Platform (Zhejiang University), etc. At the same time, redesigning on the basis of the existing framework of open source MOOC platforms are carried on in some wellknown universities in China, and more courses for SPOC are established positively [11].The structure or function of an existing MOOC platform (such as edX) is also cut properly to regenerate a lightweight MOOC platform as a SPOC platform with rapid deployment, simple structure, and satisfying requirements for learners to complete the blended learning in campus by some researchers in [12-13].

On the whole, a tremendous amount of personalized learning resources and teaching resources as well as a convenient and timely intelligent feedback system should be build in a SPOC platform, providing a convenient and intuitive statistical analysis tool for teaching design and research by teachers. It necessary to able to motivate students to conduct self-monitoring, self-testing, selfexamination, self-reflection and other activities to create a comfortable, resource-based, contextual, and collaborative learning environment for them, fully embodying the modern teaching idea of the mode, which teachers as the leading status and the students as the main body status [6]. From the views of helping students to carry out blended learning process, encouraging, guiding and inspiring students, enhancing their interests and enthusiasm for learning, conducting to cultivate students' self-learning abilities, improving students' learning motivation[14-15], and promoting the implementation of the teaching mode of flipped classroom for SPOC. The key technologies on developing of a SPOC platform are the following:

\subsection{Identity on face recognition based on emotion calculation}

Whether MOOC platforms or other traditional online teaching platforms, the design of learning behaviours of management function for learners is not perfect [3]. For example, the teacher cannot know whether an online learner is the student himself or not. Face recognition is a suitable method for verification on online learner identity and has been widely used in practice. Recently, a set of famous face recognition algorithms, such as Local Binary Patterns (LBP) [16], face recognition based on self-adaptive direction-local ternary pattern[17], face recognition algorithm based on orthogonal gradient difference local directional pattern [18], face recognition algorithm based on multi-scale block local binary and quad-tree decomposition[19], etc., can extract the location features of face detection effectively and accurately describe the essential features of the image for identity verification.

However, simple face recognition methods cannot identify the emotional state of online learners in real time online learning environment accurately. From the view of learner cognition, face expression recognition can accurately analyse the online real-time learning state and psychological activities of learners to a certain extent. Through the SPOC platform, teachers can discover whether learners have problems or not timely, such as distracting learning or have learning difficulties, and provide personalized learning resource recommendation and learning guidance services in time. Although the computer vision algorithm on framework of Face++ supports face features on extraction, face tracking positioning, face expression extraction and analysis from pictures or realtime video [11]. Therefore, how to combine identity based on face recognition with emotion calculation, and apply them in learning supervision module in SPOC platform by using framework of Face++, so that teachers can recognize online learners' learning emotions (action intentions) automatically to complete real-time supervision of the learning state of learners. It is one of the key technologies that are needed to solve in developing of a SPOC platform.

\subsection{Course creating, editing and sharing}

Course is more focused on teaching level in MOOC platforms, but data exchange or sharing of the digital teaching resource library with other teaching management platforms are not enough [20].

A variety of course templates should be designed in the SPOC platform to provide convenience for teachers to choose, so that teachers can easily create a new course that based on the existed course template wizard. A powerful course content editing function is needed in each course template, where the course resources can be added, such as 
course micro video and so on [3]. The editing function involve some sub-functions at least such as course video editing, preventing dragging forward, supporting video playback, facilitating the insertion of auxiliary learning objects, providing hyperlinks to other teaching or learning platforms with their associated learning resources which are required to teaching for a small and specific group of learners. Of course, this is the same as the course design method in some MOOC platforms in domestic currently.

Additionally, courses in SPOC platforms should have functions of clone or mapping for sharing [3]. That is to say, an existed course could be copied directly or indirectly for other teachers who are required and the course can be reedited or modified according to willingness on teachers.On one hand, it is possible to share course resources efficiently and on the other hand, courses can be redesigned for different learners to realize the process of personalized learning. Therefore, in the module of course zone in a SPOC platform, in addition to providing main functions of course overview, course video online, course live, learning resource release, and online tutoring for teachers, it is also necessary to pay more attention to the lower framework designing of the course content knowledge points for developers to integrate some rich but fragmented media resources organically according to the course system structure.

\subsection{Analysis of online learning behaviour}

Analysis of online learning behaviour is mainly based on the record data of teachers and students by SPOC platform for learning process. Based on visual statistics and some types of data mining methods, in order to get the purpose of achieving a more comprehensive assessment of learners. It is the most important of the function in a SPOC platform.

At present, online learning behaviour is reflected by the web $\log$ analysis of the teaching platform, which is realized by the application of relevant monitoring software. For example, data mining methods are used to mine web server logs and background databases of the system [21].Using web usage mining technology to analyze student's access behaviour on learning frequency, resident time, and so on [21-22]. As the most of the LMS (Learning Managed System), include some MOOC platforms, a monitoring system for practical application of online learning behaviour analysis is established [23].

Although teachers could use the classification method on data mining effectively to research the learning behaviour with related data has become a necessary and important in MOOC or SPOC, how to develop machine learning mechanism effectively to track and analyse of the learning data for various students in the monitoring system in the SPOC platform, such as the data for login the platform, watching video, exercising and testing, etc., and feedback to the learners in real time in the form of visual charts, so that learners can know their weaknesses in time and improve their learning habits accordingly. It is also a very important research field that needs to be focused on in the development of a SPOC platform.

\subsection{Exercising or examining on subjective items}

In the application requirements of SPOC, the process of exercising or examining is completed in a SPOC platform by students peer assessment system mostly. Because some exercising and examining items, such as subjective questions have no standard answers, and these types of questions can only be scored manually [12].

However, discrepancy will be existed by students peer assessment and lack of impartiality. A certain number of assignments will be selected randomly to teachers to evaluate the student's score according to the student's scores in some evaluation systems in MOOC platforms or other teaching platforms on web. But, compared with MOOC, the number of students for course learning in SPOC is small, and the sample space of students' mutual evaluation is small, which makes students raise questions for reasonableness of the their score. Additionally, for some SPOC courses in subject of engineering, during the course of exercising or examination, learners need to use specific software or hardware platforms with some integrated environment (tools) for supporting to complete some types of subjective items, such as chart drawing, architecture designing, programming, and so on. Most of the domestic MOOC platforms can only complete some subjective problem exercises or exams in form of text, such as Q\&A, the ability of third-party tools integration is not powerful yet. So, how to according to the features on the course and cognitive ability of small-scale learning group, integrating the visualized, diversified third-party platforms and tools in a SPOC platform effectively which enable learners to complete the process of exercising or examining online for some types of subjective items(chart drawing, architecture designing, programming) more conveniently, and develop standardized, scientific, and systematic scoring standards to enable students to evaluate each other relatively fair. It is also one of the key development techniques of the SPOC platform.

\section{Conclusions}

As an expansion and optimization of MOOC, SPOC has been widely used in many universities in domestic and abroad. The SPOC platform which is based on local campus is the need for the rapid development of intelligent learning, personality development on students and educational collaborative innovation in the post-MOOC era [24].

In practical application, although the SPOC platform is aimed at a specific and small-scale users group, the SPOC platform still needs to be able to handle a large number of current requests to ensure the application safety and stability of data accessing or storage in big data environment. Additionally, key technologies which are 
listed above in this paper should be put into implementation for developing a SPOC platform by developers.

\section{Further researches}

In further research on SPOC platform development, in my opinion, firstly, with the influence of rapid development of knowledge updating and the concept of life-long learning, the ubiquitous learning that based on mobile terminal devices, such as smart phones and tablet PCs will be further developed [3]. The construction of targeted and distinctive mobile learning resources and smart education mode which is based on SPOC is an important direction for SPOC platform development. Secondly, during the process of management on teaching behaviour and learning behaviour in blended teaching mode of SPOC, how to provide formative assessment data and consciousness assessment data for learners accurately by SPOC platform to improve the initiative in online learning. At the same time, function of data statistics and motivational observation could be completed by teachers through the SPOC platform, to satisfy the learning requirements for deferent learners in deferent learning phase [25].Thirdly, how to cut some nonessential auxiliary functions for a certain local user group, without affecting the running performance, reliability, stability, toughness, safety, etc., to form a flexible and usable SPOC platform with good expansibility. It is also one of the future researches in this paper.

\section{Acknowledgments}

This work was supported by the Foundation of "Massive Open Online Course on Software Engineering" of Anhui Province under Grant No. 2015mooc104, "Software Engineering-Excellent Resource Sharing Course" of Anhui Province under Grant No. 2016gxk048, "Research on Software Exploratory Testing and Its Key Technology" of Anhui SanLian University under Grant No.KJZD2017008, and "Teaching Team of Software Engineering Course" of Anhui SanLian University under Grant No. 15zlgc029.

As the corresponding author, here, I would like to express my heartfelt gratitude to all authors of the references which are listed at the end of this paper.

\section{References}

1. X.M. Sang, Reflection on MOOCs Fervor, Journal of China Higher Education Research. Issue 6 (2014), p 510.

2. Z.S. Chen, Discussion on Key Technical Elements of MOOC Platform Construction, CCF (2013).

3. H.D. Yin, Design of SPOC Teaching Platform in the Post-MOOC Period, Journal of Jiangsu Radio \& Television University. Issue 4 (2015), p 44-50.
4. P. Zhou, The Exploration and Inspiration on SPOC Localization, Journal of Chendu University: Educational Sciences Edition. Issue 5 (2016), p 108112.

5. J.J. Yu, Design and Application on Self-learning System Based on SPOC, Journal of Xichang College. Issue 1 (2017), p 57-61.

6. T.T. Lv, N. Wang, A Study on the Establishment and Effect of the Flipped Classroom Mode for SPOC + Teaching Resource Platform as Applied in College English Teaching, Journal of CET China Educational Technology. Issue 5 (2016), p 85-90.

7. B. He, Y. Cao, SPOC: MOOC-based Innovation of Teaching Processes, Journal of CET China Educational Technology. Issue 3 (2015), p 22-29.

8. R. Chen, C.Yang, Blended Learning for SPOC, Journal of Distance Education in China. Issue 5 (2015), p 4247.

9. X.H. Su, L.L. Zhao, L.Ye and Y.H. Zhang, Exploration and Practice of blended Teaching Based on MOOC + SPOC, Journal of China University Teaching. Issue 7 (2015), p 60-65.

10. X.F. Lin, Q.T. Hu and C.L. Deng, Research on Innovative Ability Cultivation Mode Based on SPOC, Journal of E-education Research. Issue 10 (2015), p 46-57.

11. H. Lu, Z.B. Hu, Research and Application of a SPOC Platform for Blended Teaching, Journal of China Modern Education Equipment. Issue 1 (2017), p 11-14.

12. Y.M. Tan, Research on Development Technologies for Lightweight MOOC Platform, MASTER'S THESIS of Yunnan University, 2015.

13. S.C. Huang, The Design and Realization of Lightweight MOOC Platform for Adult Education, MASTER'S THESIS of Hunan University, 2017.

14. T.T. Lv, H. Zhang and N. Wang, Study on the Influence of Automatic Feedback Based on Digital Writing Resource Platform on College Students 'English Writing, Journal of E-education Research. Issue 6 (2015), p 93-99.

15. N. Wang, An Exploratory Study of Digital Writing Teaching Based on Experiencing English Writing Teaching Resource Program, Journal of Modern Educational Technology. Issue 4 (2014), p 52-59.

16. Y.J. Lu, J.J. Fang, Human eye positioning algorithm based on improved multi-block local binary pattern, Journal of Modern Electronic Technique. Issue 11 (2017), p 58-60.

17. Z.H. Jin, D.H. Zhang, H.J. Gao and Y.X. Su, Face Recognition Based on Self-adaptive Direction-local Ternary Pattern, Journal of Science Technology and Engineering. Issue 27 (2017), p 249-254. 
18. H.X. Yang, J. Liu, M.J. Zhang and J.F. Zeng, Progress Face Recognition Algorithm Based on Orthogonal Gradient Difference Local Directional Pattern, Journal of Laser \& Optoelectronics. Issue 4 (2018), p 144-150.

19. X.H. Deng, H.W. Liu, Face recognition algorithm based on multi -scale block local binary and quad -tree decomposition, Journal of TV Engineering. Issue 9 (2017), p 166-170.

20. X.B. Han, L.N. Cheng and J.G. Cheng, Analysis and Design of the Educational Perspective of MOOCs, Journal of E-education Research. Issue 1 (2014), p 45 51.

21. X.W. Sun, Online learning behavior analysis based on SPOC platform log data and influencing factors, Journal of Shenyang Normal University: Nat Sci Ed. Issue 1 (2017), p 103-107.

22. M. Huang, X. Liang and X.L. Gu, Introduction on Massive Open Online Course (Publishing House of Electronics Industry, Beijing, 2015)

23. A.P. Xiao, C.F. Jiang, Investigation and Research on Web-based Learners, Journal of Open Education Research. Issue 1 (2009), p 75-80.

24. Z.T. Zhu, N.Z. Liu, New Trends of Online Learning in the "Post-MOOC Era", Journal of Open Education Research. Issue 3 (2014), p 36-43.

25. H.D. Yin, Exploration of Blended Teaching Model based on Fanya SPOC Platform during the PostMOOC Period, Journal of Modern Educational Technology. Issue 11 (2015), p 53-59. 